\title{
WEIGHTED ESTIMATES FOR ROUGH SINGULAR INTEGRALS WITH APPLICATIONS TO ANGULAR INTEGRABILITY, II
}

\author{
FEng LiU, Ronghui LiU And HuOXIONG Wu
}

Abstract. This paper is devoted to studying certain singular integral operators with rough radial kernel $h$ and sphere kernel $\Omega$ as well as the corresponding maximal operators along polynomial curves. The authors establish several weighted estimates for such operators by assuming that the kernels $h \equiv 1$ and $\Omega \in \mathscr{F}_{\beta}\left(\mathrm{S}^{n-1}\right)$, or $h \in \Delta_{\gamma}\left(\mathbb{R}_{+}\right)$and $\Omega \in W \mathscr{F}_{\beta}\left(\mathrm{S}^{n-1}\right)$. Here $\mathscr{F}_{\beta}\left(\mathrm{S}^{n-1}\right)$ denotes the Grafakos-Stefanov kernel and $W \mathscr{F}_{\beta}\left(\mathrm{S}^{n-1}\right)$ denotes the variant of Grafakos-Stefanov kernel. As applications, the boundedness of such operators on the mixed radial-angular spaces $L_{|x|}^{p} L_{\theta}^{q}\left(\mathbb{R}^{n}\right)$ are obtained. Meanwhile, the corresponding vector-valued versions are also given. Moreover, the bounds are independent of the coefficients of the polynomials in the definition of operators.

Mathematics subject classification (2010): 42B20, 42B25.

Keywords and phrases: Singular integral, maximal singular integral, maximal operator, $\mathscr{F}_{\beta}\left(\mathrm{S}^{n-1}\right)$, mixed radial-angular space.

\section{REFERENCES}

[1] A. Al-Salman And Y. Pan, Singular integrals with rough kernels in $L \log L\left(\mathrm{~S}^{n-1}\right)$, J. London Math. Soc., 66, 2 (2002), 153-174.

[2] J. BERGH AND J. LÖFSTRÖM, Interpolation spaces: An introduction, Grundlehren der Mathematischen Wissenschaften 223, Springer-Verlag, Berlin-New York, 1976.

[3] F. Cacciafesta And R. LuCÀ, Singular integrals with angular integrability, Proc. Amer. Math. Soc., 144, 8 (2016), 3413-3418.

[4] A. P. CALDERón AND A. Zygmund, On the existence of certain singular integrals, Acta Math., 88, (1952), 85-139.

[5] A. P. Calderón and A. Zygmund, On singular integral, Amer. J. Math., 78, (1956), 289-309.

[6] R. R. COIFMAN AND G. Weiss, Extensions of Hardy spaces and their use in analysis, Bull. Amer. Math. Soc., 83 (1977), 569-645.

[7] W. C. ConnetT, Singular integrals near $L^{1}$, in Harmonic analysis in Euclidean spaces (Proc. Sympos. Pure Math., Williams Coll., Williamstown, Mass., 1978, Part 1), 163-165, Amer. Math. Soc., Providence, R.I., 1979.

[8] R. Coifman and R. Rochberg, Another characterization of BMO, Proc. Amer. Math. Soc., 79, 2 (1980), 249-254.

[9] A. Córdoba, Singular integrals, maximal functions and Fourier restriction to spheres: the disk multiplier revisited, Adv. Math., 290, (2016), 208-235.

[10] P. D'ANCONA AND R. LUCÀ, On the regularity set and angular integrability for the Navier-Stokes equation, Arch. Rational Mech. Anal., 221, (2016), 1255-1284.

[11] J. DuoAndikoetXea And O. OruetXebarRia, Weighted mixed-norm inequalities through extrapolation, Math. Nachr., 292, (2019), 1482-1489.

[12] J. DuOANDikoetXeA AND J. L. Rubio DE FRAnCIA, Maximal and singular integral operators via Fourier transform estimates, Invent. Math., 84, 3 (1986), 541-561.

[13] D. FAN, K. GUO AND Y. PAN, A note of a rough singular integral operator, Math. Inequal. Appl., 2, 1 (1999), 73-81. 
[14] D. FAN AND Y. PAN, Singular integral operators with rough kernels supported by subvarieties, Amer. J. Math., 119, 4 (1997), 799-839.

[15] D. FAN AND S. SATO, A note on the singular integrals associated with a variable surface of revolution, Math. Inequal. Appl., 12, 2 (2009), 441-454.

[16] R. Fefferman, A note on singular integrals, Proc. Amer. Math. Soc., 74, 2 (1979), 266-270.

[17] C. FefFerman And E. M. Stein, Some maximal inequalities, Amer. J. Math., 93, (1971), 107-115.

[18] L. GRAFAKOS AND A. STEFANOV, $L^{p}$ bounds for singular integrals and maximal singular integrals with rough kernels, Inidiana Univ. Math. J., 47, 2 (1998), 455-469.

[19] S. HoFMANN, Weighted norm inequalities and vector valued inequalities for certain rough operators, Indiana Univ. Math. J., 42, 1 (1993), 1-14.

[20] W. LI, Z. SI AND K. YABUTA, Boundedness of singular integrals associated to surfaces of revolution on Triebel-Lizorkin spaces, Forum Math., 28, 1 (2016), 57-75.

[21] F. LIU AND D. FAN, Weighted estimates for rough singular integrals with applications to angular integrability, Pacific J. Math., 301, 1 (2019), 267-295.

[22] F. LIU, S. MAO AND H. WU, On rough singular integrals related to homogeneous mappings, Collect. Math., 67, 1 (2016), 113-132.

[23] F. LIU AND H. WU, Rough singular integrals and maximal operators with mixed homogeneity along compound curves, Math. Nachr., 287, 10 (2014), 1166-1182.

[24] J. NAmAZI, A singular integral, Proc. Amer. Math. Soc., 96, (1986), 201-219.

[25] S. S ATO, Estimates for singular integrals and extrapolation, Studia Math., 192 (2009), $219-233$.

[26] C. ZHANG, Weighted estimates for certain rough singular integrals, J. Korean Math. Soc., 45, 6 (2008), 1561-1576. 